irrigation system of enormous extent, together with the remnants of a large dam. There is also a copper tool, which is said to be an authentic mining imple. ment. These finds are ascribed to a vanished race, and on account of the diminutive size of the stairways, it is suggested that its members were pygmies. The collections have been placed at the disposal of the Ethnological Department of the University of the Witwatersrand and are said to be regarded by the Department as very important. As Mr. van der Merwe is a layman in ethnological matters, the verdict of experts in the cultures of the natives of South Africa will be awaited with interest. As a rule, unfortunately, previous claims to the discovery of new cultures and vanished races have not survived their impartial scrutiny.

\section{A New South African Culture?}

A ClAIM to have distinguished a new material culture in South Africa is put forward by Dr. Ir. E. C. N. Van Hoepen, director of the National Museum, Bloemfontein (Argoeologiese Navorsing, Dl. i St. 5), in describing a remarkable stone pipe from a shelter near Bethlehem. Its peculiarity lies in the ornamentation, a system of curved grooves and on one side a sinuous ridge ending in a reversed $\mathrm{E}$, representing a snake. Similar pipes have previously been described, one of clay from the ash-heaps of stone huts at Vegkop by Van Riet Lowe and another of stone by Stow. Van Riet Lowe attributed the pipe he described to the Leghoya, dating the huts at about 1790, but Dr. Van Hoepen does not consider his reasoning or evidence satisfactory, and points out that stone huts are not a characteristic of Bantu culture, the Leghoya themselves using conical grass thatched huts, according to Stow. He himself sees in the pipes and the shelters closer affinities with Hottentot, Bushmen, and Xosa, but concludes that the three characters, the stone pipes, the stone huts and the ornamentation do not belong to any known African culture. We are, therefore, he holds, dealing with something new, a culture for which the name 'stone-hut' culture is proposed. This view, important as it is for the history of South African cultures, should be accepted with some caution. Its confirmation by further evidence will be awaited with interest.

\section{American Archæologists in Yugoslavia}

AT a meeting of the American Anthropological Association held in Atlantic City at the end of December, Dr. Vladimir J. Fewkes described the work during the past summer of a joint archæological expedition of the Peabody Museum, the Fogg Art Museum, Harvard University, and the American School of Prehistoric Research in Jugoslavia. Some 150 archæological sites were visited and examined. A large proportion of these were found to belong to Greek, Roman, Macedonian or Byzantine cultures. The most considerable undertaking of the expedition was the excavation of the neolithic site at Starcevo, of which the investigation had been begun in the previous year. The settlement is dated at about 2500 B.C. and is found to consist of a number of irregularly placed groups of semi-subterranean dwel. lings, of which the foundations have been exposed. Among the material found are crude but well-made cooking pots, painted pottery, needles, awls and spatulas of bone, stone knives and celts, shells, and small libation tables of baked clay. The settlement was one of small farmers with domesticated animals, who supplemented their food supply by hunting and fishing. In a report of the communication from Science Service, Washington, D.C., Dr. Fewkes is said to have stated that the expedition had gathered fresh evidence relating to the early trade routes of this part of Europe, an area he regards as the archæological key-region of the Balkans.

\section{Spectrum Analysis}

THE increasingly great interest now being shown in spectrum analysis is well exemplified by two recent developments in the United States. The first of these was the setting up by the American Society for Testing Materials of a committee (E-2) on spectrographic analysis in its application to analytical and metallurgical problems. This committee is now at work and it is probable that tangible results will be forthcoming in the near future. News of the second development has just reached Great Britain. It has been decided that one of the lines of work to be intensively pursued at the magnificently equipped spectroscopic laboratory of the Massachusetts Institute of Technology is the application of spectrum analysis to industrial and related problems. In order that as close touch as is possible may be made with industrial problems, a research conference is to be held at the Institute during the week beginning July 17, and it is hoped that at this conference industrial experts, academic research workers and manufacturers of spectroscopic equip. ment will meet and discuss those aspects of the problem with which they are individually familiar. It is clear that one of the earliest developed aspects of spectroscopy is again coming very much to the fore, and that the dreams of some of the early spectroscopists regarding the general use of this technique in industry are coming measurably nearer realisation.

\section{Machine Age's Starvation Predicted}

THE comparatively rapid depletion of the earth's available resources in this mechanical age was considered by Prof. R. A. Gortner, of the University of Minnesota, in a paper before the American Association for the Advancement of Science in December (Science Service, Washington, D.C.). It is pointed out that irreplaceable stores of natural resources absolutely essential to modern industrial civilisation are disappearing into the 'maws of industry' and so are wastefully dissipated over the earth. While the publicity of technocracy directs attention to the part played by mechanical energy in remaking economic conditions, the shelves in some of Nature's cupboard are showing signs of exhaustion of the materials necessary for a mechanical age. In particular, Prof. Gortner mentions the approaching exhaustion of copper, antimony, tin, lead, zinc, chromium, manganese, nickel and iron, which are stored in parts 
of the earth accessible to man. The rate of use of some of these metals is doubling each decade. We still use tin-foil for wrapping up sweets and cigarettes. At the present mining rates, iron will be exhausted in Germany in about fifty years and in the United States in about a hundred years. The supply of sulphur in the United States will fail in fifteen years, the coal of Germany in less than a thousand years and of the United States, notwithstanding its huge lignite deposits, in less than fifteen hundred years. It looks as if the machine age may starve to death before long, a victim of to-day's profligate use of metals, coal and oil. Water power, alcohol from vegetation, solar energy, etc., are at present totally inadequate to replace oil and coal. Will future civilisations look back upon the industrial civilisation of the twentieth century as an age of robbery?

\section{U.S. Bureau of Standards}

THE annual report of the Director of the Bureau of Standards (Government Printing Office, Washington, 1932) shows the trend of scientific developments during last year. The increase in the industrial applications of very low temperatures has made it advisable to extend the scale downwards from $-100^{\circ} \mathrm{C}$. to $-259^{\circ} \mathrm{C}$. and a temporary scale covering this range has been established. Fire tests have been made on the new welded steel floors which are now being used in buildings. They consist of steel floor plates welded to beams spaced two feet apart. Tests were made with fire both above and below the floor. Gas appliances found quite satisfactory at sea level develop defects when used in cities at high altitudes. The causes of these defects are being investigated. Perhaps the most spectacular advance made during the year has been to increase the accuracy of the primary frequency standard to one part in ten million. Regular transmissions of standard highfrequency waves at a frequency of 5,000 kilocycles per second are broadcast every Tuesday for four hours. The accuracy obtained is one cycle per second, that is, one part in five million. The ionised layer in the atmosphere has been determined to be the major controlling factor in the long distance transmission of radio waves. The measurement of the height of this layer is of primary importance in interpreting transmission conditions and increasing our knowledge of radio wave transmission. Using improved equipment, these measurements were made on one day in each week throughout the year. An automatic recorder is now in use which makes continuous measurements. Useful work is done in making careful analyses of samples of ores, alloys, pure metals, cement and pure chemicals. These samples are sold to industrial laboratories and are used for checking their own methods and results. This plan has contributed greatly to the precision of the analytical work in these laboratories and the project is self-supporting.

\section{Miners' Nystagmus}

Two reports on this subject by a Committee of the Medical Research Council were issued in 1922 and
1923. The principal finding of the Committee was that the chief symptom of this disease-the involuntary oscillation of the eyeballs-is caused by an insufficiency of the light reaching the eyes of the miner while at work, and that the most important measure of prevention is to secure for the miner at work adequate illumination. Nevertheless, in spite of considerable improvement in the illumination of mines, the incidence of the disease has, on the whole, steadily increased, for compensation on account of this disability was paid to 10,638 persons in 1930 ; this is the largest number, with one exception, during the past twenty-three years. The Medical Research Council has therefore considered it advisable to reconstitute the Committee, which has now issued a third report on the subject (Special Rep. Series, No. 176. H.M. Stationery Office. 9d.). This reaffirms, in the strongest terms, the conclusions of the former committee. There should be constant illumination of 0.25 foot-candle on the coal face, and it is understood that there are recent developments in the direction of improving illumination in mines. To account for the continued prevalence of the condition, it must be recognised that the oscillation of the eye. balls is but a part of the disease, and various psychoses and neuroses are also present. The practical treatment of the disease should consist in the elimination of a hopeless dependence on compensation by the provision of opportunities for work of some kind, even if restoration of full work underground has to be preceded by a period of work in dayljght.

\section{Guard Posts for Road Island Refuges}

ILLUMiNATED guard posts or 'bollards' are now gradually coming into use on all types of roads which carry fast vehicular traffic. In the Osram G.E.C. Bulletin for February, a description is given of a well-designed guard post which should prove useful not only by indicating the refuge to pedestrians, thus prompting them to cross the road at that point, but also to motorists; thus removing a frequent cause of accidents. It is a luminous pillar $4 \mathrm{ft}$. high, the light being emitted only from the side which faces the traffic. The back of the pillar is made of solid steel tube, so that in the event of a smash the damage done will be probably much less than if it were made of cast iron. The head of the bollard is arranged as a lantern with the red glass fixed around half its circumference. The red glass is generally illuminated by a sixty-watt lamp but sometimes a small auxiliary lamp is used as well so as to prevent a complete 'black out' if the main lamp is extinguished. Complete isolation of the bollard from the electric supply in the event of damage is easily obtained by opening a door near the ground level where the time-switch and fuses are fixed.

\section{Researches on Sedimentation}

The report of the Committee on Sedimentation for the two years 1930-1932 has been published under the auspices of the Division of Geology and Geography of the U.S. National Research Council as National Research Bulletin No. 89, 1932 (pp. 229, price 